\title{
Lipofibromatous Hamartoma of the Upper Extremity: Report of Two Cases
}

\author{
(D) Zehra Filiz Karaman ${ }^{1}$, (D) Ibrahim Karaman², (D) Abdulhakim Coşkun ${ }^{1}$ \\ 1 Erciyes University Faculty of Medicine, Department of Pediatric Radiology, Kayseri, Turkey \\ 2Erciyes University Faculty of Medicine, Department of Orthopaedics and Traumatology, Kayseri, Turkey
}

\section{Abstract}

Lipofibromatous hamartoma is a rare, slow-growing, benign, fibrofatty tumor-like condition. The upper extremity nerves are commonly involved. It is characterized by thickened axonal bundles with epineural and perineural fibrosis and fatty infiltration around the axonal bundles. Macrodactyly is a characteristic symptom in one-third of cases. Treatment options are differentiated according to the symptomatology. The diagnosis can be made by ultrasonographic and magnetic resonance imaging findings for those obviating diagnostic biopsy.

Keywords: Macrodactyly, median nerve, ulnar nerve, lipofibromatous hamartoma

\section{INTRODUCTION}

Lipofibromatous hamartoma (LFH) is a rare condition caused by fibroadipose tissue proliferation within peripheral nerves. Endoneural and perineural fibrosis thicken the axonal bundles. Fat tissue infiltrates the nerves separating the axonal bundles. Macrodactyly is associated with LFH in about one-third of cases (1).

LFH is a non-hereditary, congenital condition that is often seen in young patients. The most commonly affected nerve is the median nerve. In the literature, the involvement of other peripheral nerves is also reported (2).

We present two cases with LFH, one in the median nerve, the other in both the median and ulnar nerves.

\section{CASE PRESENTATIONS}

\section{Case 1}

An 11-year-old boy presented to our institution with a complaint of mass-like swelling on the palmar aspect of his left hand and first finger. According to his parents, the mass presented in infancy and has grown slowly as the boy grows.
He had a palpable mass on the thenar side of his left hand extending to the volar aspect of his first and second fingers in physical examination. Macrodactyly was seen in the first finger (Figure 1). There was tenderness to palpation.

On sonography, the extremely thick median nerve was seen at the distal forearm, wrist, and midhand extending to the fingers. Lipomatous tissue infiltration was seen in the median nerve, at the thenar site, and the first finger's volar aspect, seen as echogenic structures (Figure 2, 3).

On magnetic resonance imaging (MRI), the thickened median nerve was seen with serpiginous hypointense nerve fibers surrounded by fatty tissue giving the pathognomonic "coaxial cable-like appearance" at axial images.

\section{Case 2}

An 11-year-old girl presented to our institution with a complaint of soft tissue swelling at the palmar aspect of her left hand, especially on the fourth metacarpal.

On MRI, median and ulnar nerves were thickened at wrist and mid hand, typical "coaxial cable-like appearance" was seen at axial images, "spaghetti-like appearance" at coronal 


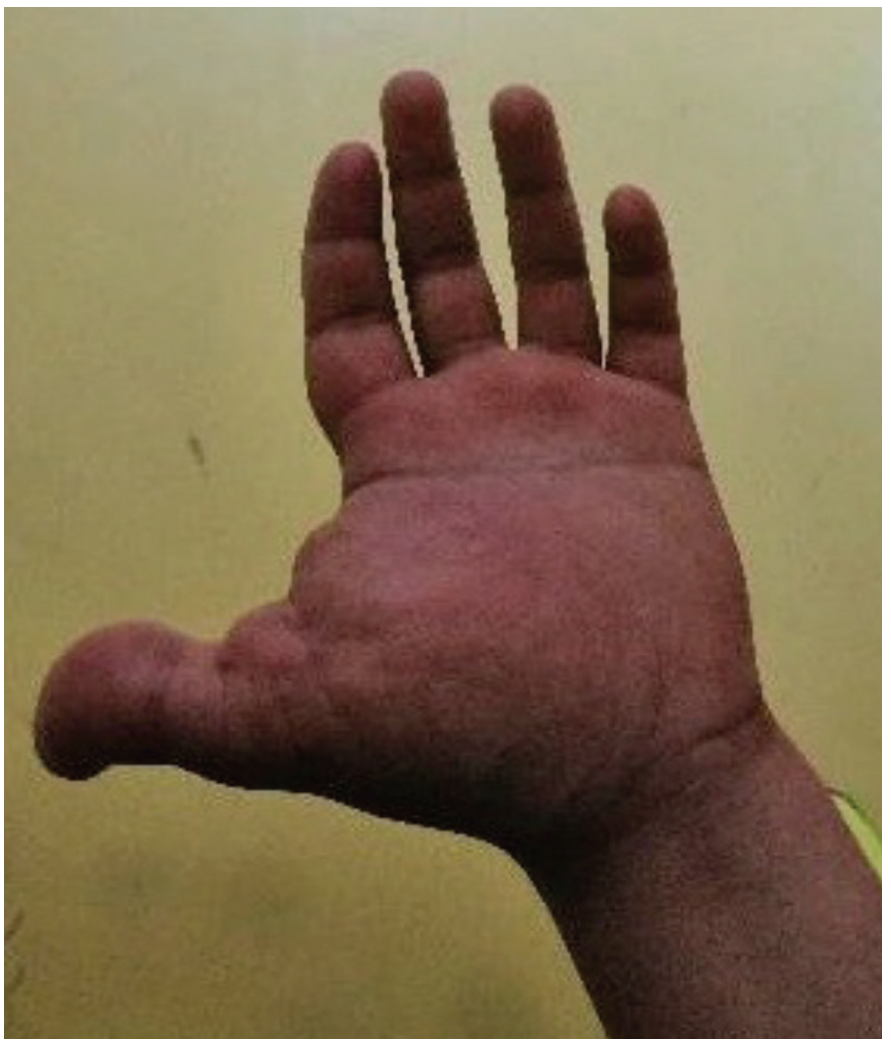

Figure 1. An 11-year-old boy with LFH of the median nerve. Enlargement of the thenar side of the left hand and macrodactyly at the first finger is seen

LFH: Lipofibromatous hamartoma

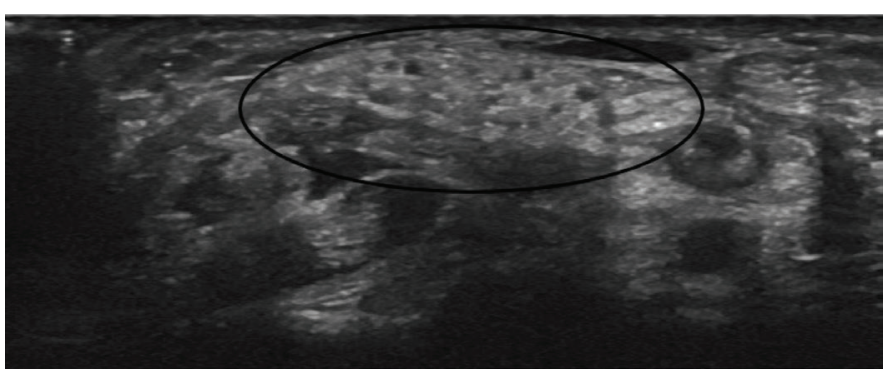

Figure 2. An 11-year-old boy with LFH of the median nerve. The extremely thick median nerve (circle) is seen in axial planes of sonography of the wrist

LFH: Lipofibromatous hamartoma

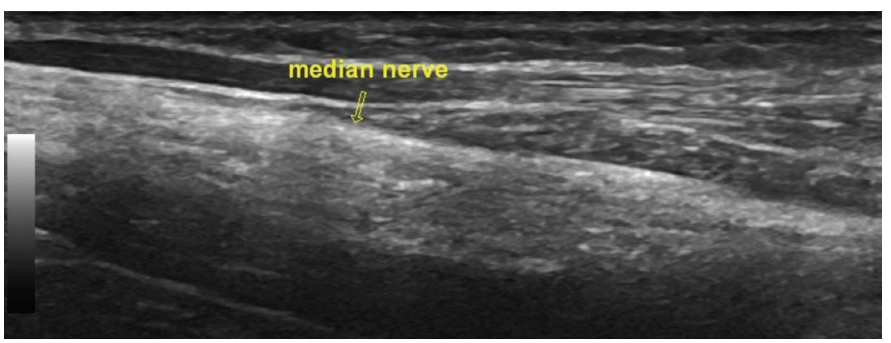

Figure 3. An 11-year-old boy with LFH of the median nerve. The extremely thick median nerve (arrow) is seen in sagittal planes of sonography of the distal forearm

LFH: Lipofibromatous hamartoma images, indicating fibrolipomatous infiltration of both nerves (Figure 4, 5).

\section{DISCUSSION}

LFH is a rare, slow-growing, tumor-like condition formed by the infiltration of the peripheral nerves by fibroadipose tissue (3).

The etiology is unknown. It is congenital, and the vast majority of cases are seen in childhood and young adulthood (4).

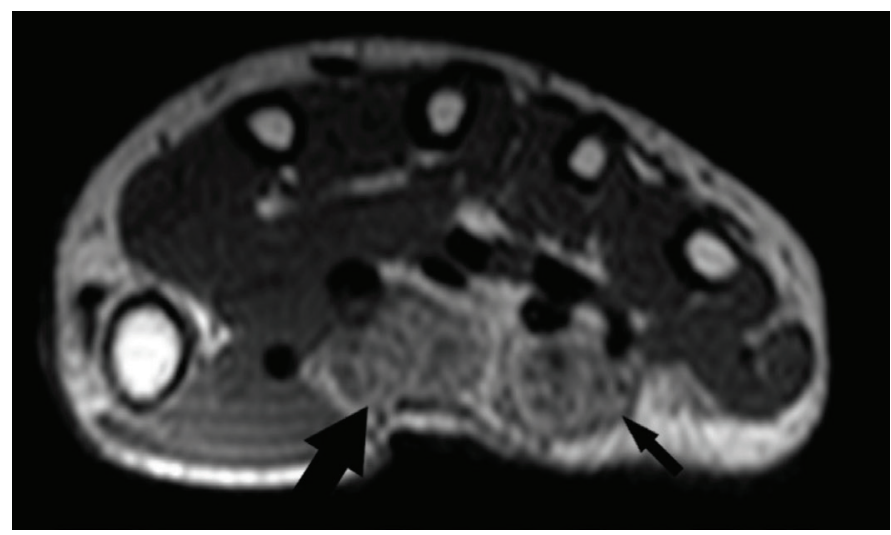

Figure 4. An 11-year-old girl with LFH of the median and ulnar nerves. Axial T1-weighted images through the wrist. The coaxial cable-like appearance of both the median (thick arrow) and ulnar nerve (thin arrow)

LFH: Lipofibromatous hamartoma

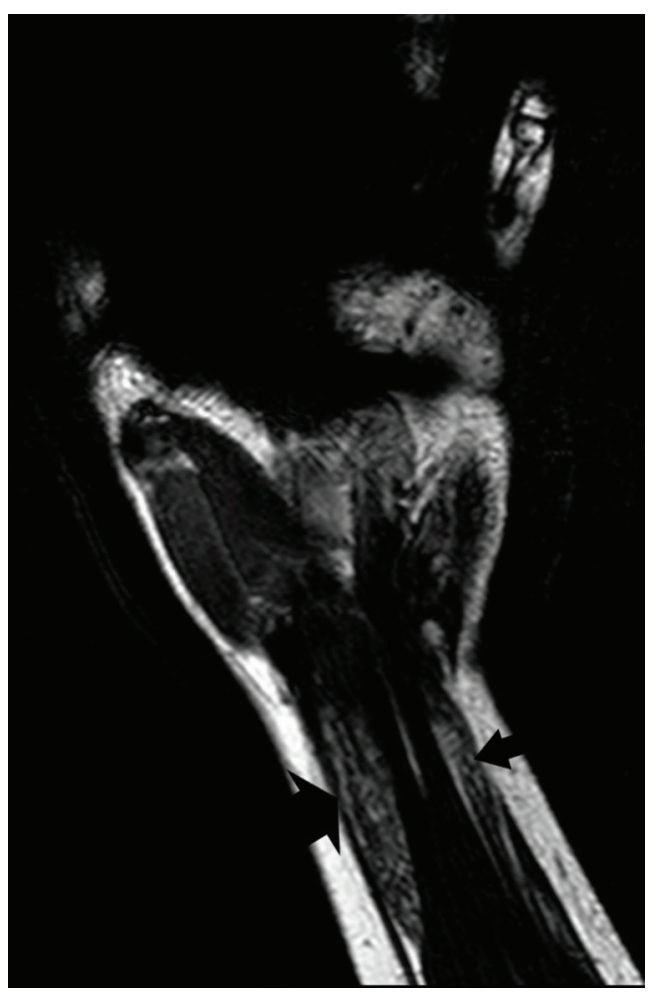

Figure 5. Coronal T1-weighted images of the wrist and distal forearm. The spaghetti-like appearance of both the median nerve (thick arrow) and ulnar nerve (thin arrow) 
According to a 2019 literature review by Marek et al. (2) there have been 329 cases of LFH with 220 median and 22 ulnar nerve involvement. In seven cases, both the median and ulnar nerves were involved. Other nerves reported were plantar foot, sciatic, brachial plexus, tibial, radial, lumbosacral plexus, obturator, and femoral (2). Median nerve involvement was seen in one of our cases, while both the median and ulnar nerve involvement was seen in the other case.

The typical presentation of median nerve involvement is carpal tunnel syndrome (5). Symptoms are often seen in the third or fourth decade. There is a long history of painless swelling since childhood. Macrodactyly is the most common characteristic finding of LFH, seen in approximately $30 \%$ of cases (1). Carpal tunnel symptoms were not present in our cases. We think it may be due to the young age of the patients.

MRI is the first choice for imaging (6). The pathognomonic findings are "coaxial cable-like appearance" in axial planes, "spaghetti-like appearance" in sagittal planes (7). This is formed by the thickening of axonal bundles with fibrosis and fatty infiltration. The sonographic findings consistently correspond to the MRI findings. Sonography may be helpful for the complete viewing of extensive lesions. Sonographic and MRI findings are accurate for diagnosis and may obviate diagnostic biopsy (1). The imaging findings were typical for the diagnosis in our cases. We did not need a biopsy for the diagnosis.

The treatment choices are different according to the symptomatology. Asymptomatic patients are observed. Prophylactic carpal tunnel release or total nerve resection are performed in symptomatic patients. For macrodactyly, available treatment choices include debulking overgrown tissue, digital amputation, and middle phalangectomy with arthroplasty (8). We decided to observe the patients for probable carpal tunnel symptoms that may manifest in the future.

\section{CONCLUSION}

LFH is a rare, slow-growing, benign, fibro-fatty, tumor-like lesion that most commonly manifests in the upper extremity nerves, mainly the median nerve. LFH must be considered in the differential diagnosis of macrodactyly. Radiological findings are characteristic and accurate for the diagnosis, thus obviating diagnostic biopsy.

\section{Ethics}

Informed Consent: Consent was obtained from the parents of the patients.

Peer-review: Externally and internally peer-reviewed.

\section{Authorship Contributions}

Concept: Z.F.K., Design: Z.F.K., I.K., Data Collection or Processing: I.K., Z.F.K., A.C., Analysis or Interpretation: Z.F.K., I.K., Literature Search: Z.F.K., A.C., Writing: Z.F.K., I.K.

Conflict of Interest: No conflict of interest was declared by the authors.

Financial Disclosure: The authors declared that this study received no financial support.

\section{REFERENCES}

1. Toms AP, Anastakis D, Bleakney RR, Marshall TJ. Lipofibromatous hamartoma of the upper extremity: a review of the radiologic findings for 15 patients. AJR Am J Roentgenol 2006;186:805-11.

2. Marek T, Mahan MA, Carter JM, Amrami KK, Benarroch EE, Spinner RJ. Lipomatosis of nerve and overgrowth: is there a preference for motor (mixed) vs. sensory nerve involvement? Acta Neurochir (Wien) 2019;161:679-84

3. Shekhan HN, Hanna T, Johnson JO. Lipofibromatous hamartoma of the median nerve: A case report. J Radiol Case Rep 2016;10:1-7.

4. Nardella D, Sohawon S, Carlier A. Lipofibromatous hamartoma of the median nerve. Three case reports. J Plast Reconstr Aesthet Surg 2009;62:e314-7.

5. Kitridis D, Dionellis P, Xarchas K, Givissis P. Giant median nerve due to hamartoma causing severe carpal tunnel syndrome. J Orthop Case Rep 2018:8:57-60

6. Sirinoglu H, Sönmez A, Sav A, Numanoglu A. Lipofibromatous hamartoma of the median nerve. Ann Plast Surg 2010;65:174-6.

7. Azeemuddin M, Waheed AA, Khan N, Sayani R, Ahmed A. Fibrolipomatous Hamartoma of the Median Nerve with Macrodystrophia Lipomatosa. Cureus 2018;10:e2293

8. Tahiri Y, Xu L, Kanevsky J, Luc M. Lipofibromatous hamartoma of the median nerve: a comprehensive review and systematic approach to evaluation, diagnosis, and treatment. J Hand Surg Am 2013;38:2055-67. 